\title{
Robust Control and Actuator Dynamics Compensation for Railway Vehicles
}

\author{
Seyed Milad Mousavi Bideleh",a,b T. X. Mei ${ }^{\mathrm{b}}$, and Viktor Berbyuk ${ }^{\mathrm{a}}$ \\ ${ }^{a}$ Department of Applied Mechanics, Chalmers University of Technology, SE 41296, Gothenburg, Sweden. \\ ${ }^{b}$ School of Computing, Science and Engineering, University of Salford, Manchester, M5 4WT, UK.
}

\begin{abstract}
A robust controller is designed for active steering of a high speed train bogie with solid axle wheel sets to reduce track irregularity effects on the vehicle's dynamics and improve stability and curving performance. A half-car railway vehicle model with seven degrees of freedom equipped with practical accelerometers and angular velocity sensors is considered for the $\mathrm{H}_{\infty}$ control design. The controller is robust against the wheel/rail contact parameter variations. Field measurement data are used as the track irregularities in simulations. The control force is applied to the vehicle model via ball-screw electromechanical actuators. To compensate the actuator dynamics, the time delay is identified online and is used in a second order polynomial extrapolation carried out to predict and modify the control command to the actuator. The performance of the proposed controller and actuator dynamics compensation technique are examined on a one-car railway vehicle model with realistic structural parameters and nonlinear wheel and rail profiles. The results showed that for the case of nonlinear wheel and rail profiles significant improvements in the active control performance can be achieved using the proposed compensation technique.
\end{abstract}

Keywords: Robust control; Active Suspension; Sensors; Actuator; Dynamics Compensation; Railways.

\section{Introduction}

Railways play an essential role in transportation nowadays. High speed, relatively cheap operation and maintenance cost as well as safe and environmental friendly service are some of the railways' most important features. The cost efficiency in railway operations can be explored from different points of views such as running speed, ride comfort, safety, wheel/rail contact wear, maintenance cost and so forth. The bogie system of high speed trains contains primary and secondary suspension components which can significantly affect the overall dynamics behaviour of railway vehicles on different operational scenarios. Therefore, special attention should be paid to the bogie suspension system design. In this regard, several passive and active systems are developed during the past few decades in order to meet various design requirements and improve the railway vehicles' performance from different

\footnotetext{
* Corresponding author

E-mail: milad.mousavi@,chalmers.se
} 
perspectives such as ride comfort, safety, and wheel/rail contact wear, see e.g. [1-6]. Although passive suspension systems might provide satisfactory running behaviour at low to medium speeds, application of such systems at high speeds might lead to a poor ride comfort and steering problems such as instability and lack of excellent curving performance.

Active elements are often used in substitution of or in combination with passive components to improve the vehicle's dynamics. The mainstream of the active control design in railway application is considered for the secondary suspension system. Orvnäs et. al. [7] designed a robust controller based on the $\mathrm{H}_{\infty}$ concept to improve ride comfort and lateral stability of carbody. The controller has been designed for a quarter-car model and tested on a full scale vehicle model developed in multibody dynamics software SIMPACK. The results shown that remarkable ride comfort improvement can be achieved by means of the proposed control technique. Colombo et. al. [8] proposed an active hydraulic anti-roll bar which limited the carbody tilt on curves. Three control strategies have been examined and the results revealed an improvement in the vehicle's running speed on curves while ride comfort remain unchanged or improved. Matamoros-Sanchez and Goodall [4] combined inerter-based suspensions with active control schemes to improve ride comfort. A novel nonlinear control strategy has been also proposed to compliment the implementation of skyhook damping. The results shown a significant vertical ride comfort enhancement with a smaller control effort. Gajdar et. al. [9] proposed an optimal and a robust controller for a wheel set system. The effects of parameters uncertainties have also been considered and a new controller designed to account for that.

One of the most elementary steps in bogie suspension design for high speed trains running on curves is to assure that the system runs stable and reflects an appropriate curving performance and steering which are mostly dominated by the primary suspension components. In this regard, several active control schemes have been studied to improve the vehicle's performance with respect to stability, curving performance, and steering, see e.g. [10-12]. Pearson et. al. [13] compared the stability performance of a classical controller and an optimal controller designed based on the linear quadratic regulator (LQR) theory for a set of operational scenarios and parameter uncertainties. The results tested on an experimental roller rig revealed that the proposed active controllers can significantly reduce the lateral motion of the bogie leading axle in comparison with to the passive case. Uncertainties in the wheel/rail contact parameters due to the track irregularities might negatively affect the controller performance. Mei and Goodall [14] designed a robust controller for active steering of a bogie with independently rotating wheels. The proposed controller is shown to be robust against the structural as well as the wheel and rail contact parameters uncertainties. The results showed that the proposed controller not only reduced the lateral motion of the wheel set but also enhanced ride comfort in comparison with to the case with passive control. The time delay due to the actuator dynamics in such actively controlled wheel sets might induce negative damping and make the system unstable. Therefore, it is necessary to compensate the time delay to be able to have the actuator output as close as possible to the ideal control command. The 
actuator dynamics effects on the suspension system performance is investigated in a few studies. The mainstream of the work on actuator delay compensation is done by taking into account the actuator dynamics during the control design process, see e.g. [15, 16]. Li et. al. [17] employed the paralleldistributed compensation technique to design a reliable fuzzy $\mathrm{H}_{\infty}$ performance analysis criterion for a Takagi-Sugeno fuzzy system with actuator delay and fault. The results revealed that better suspension performance can be achieved using the proposed scheme. Shin et. al. [18] designed a multi-level controller (which incorporated the actuator dynamics) to compensate the time delay and dynamic friction torque. The ride quality was improved by using the proposed method.

The time delay in suspension system applications is frequency dependent and should be compensated for online. Here, in addition to the weighting functions used to account for the actuator dynamics during the control design process and a PI controller which is tuned to reduce the error between the control command and the actuator output, a compensation technique which works based on the modification of the control command is proposed to further compensate the actuator dynamics and improve the active control performance.

\subsection{Motivation}

Although the robust control design of a bogie with independently rotating wheels is carried out in [14], similar problem for vehicles with solid axles has not been considered before. The motion dependency of wheels in a solid axle setup makes it more difficult to stabilize the system for such cases. Therefore, the main aim of the current study is to design a robust controller for bogie system of high speed trains with solid axles. Accelerometers, angular velocity sensors, and ball-screw electrohydraulic actuators are employed to provide a practical solution for the considered problem. Due to the actuator dynamics there is a dynamic time delay between the controller output and actuator output which may compromise system performance or even make the system unstable. Therefore, in addition to a PI controller, the time delay is identified online and is used in a second order polynomial extrapolation to predict and modify the controller command and further compensate the effects of the actuator dynamics. The performance of the proposed robust controller and actuator dynamics compensation technique is then examined on a one-car full scale railway vehicle model with realistic structural parameters, nonlinear wheel and rail profiles, and filed measurement track irregularities.

\section{Vehicle Model}

A half-car railway vehicle model shown in Fig. 1 is considered for the robust control design. The vehicle model consists of two wheel sets, one bogie frame, and a half-carbody. The bogie frame and each wheel set can make a lateral and a yaw motion, while the half-carbody only allows a lateral motion. Therefore, the vehicle model has 7 degrees of freedom (DOF). The bogie has solid axle wheel sets with linear wheel profiles. In addition to the abovementioned rigid components the vehicle model includes a set of primary and secondary suspensions. All the spring and dampers are passive and modelled as linear elements. 
The target is to design a robust controller for active steering of the vehicle. The control torque is then applied to the wheel sets via a set of electromechanical actuators connecting the wheel sets to the bogie frame in the longitudinal direction.
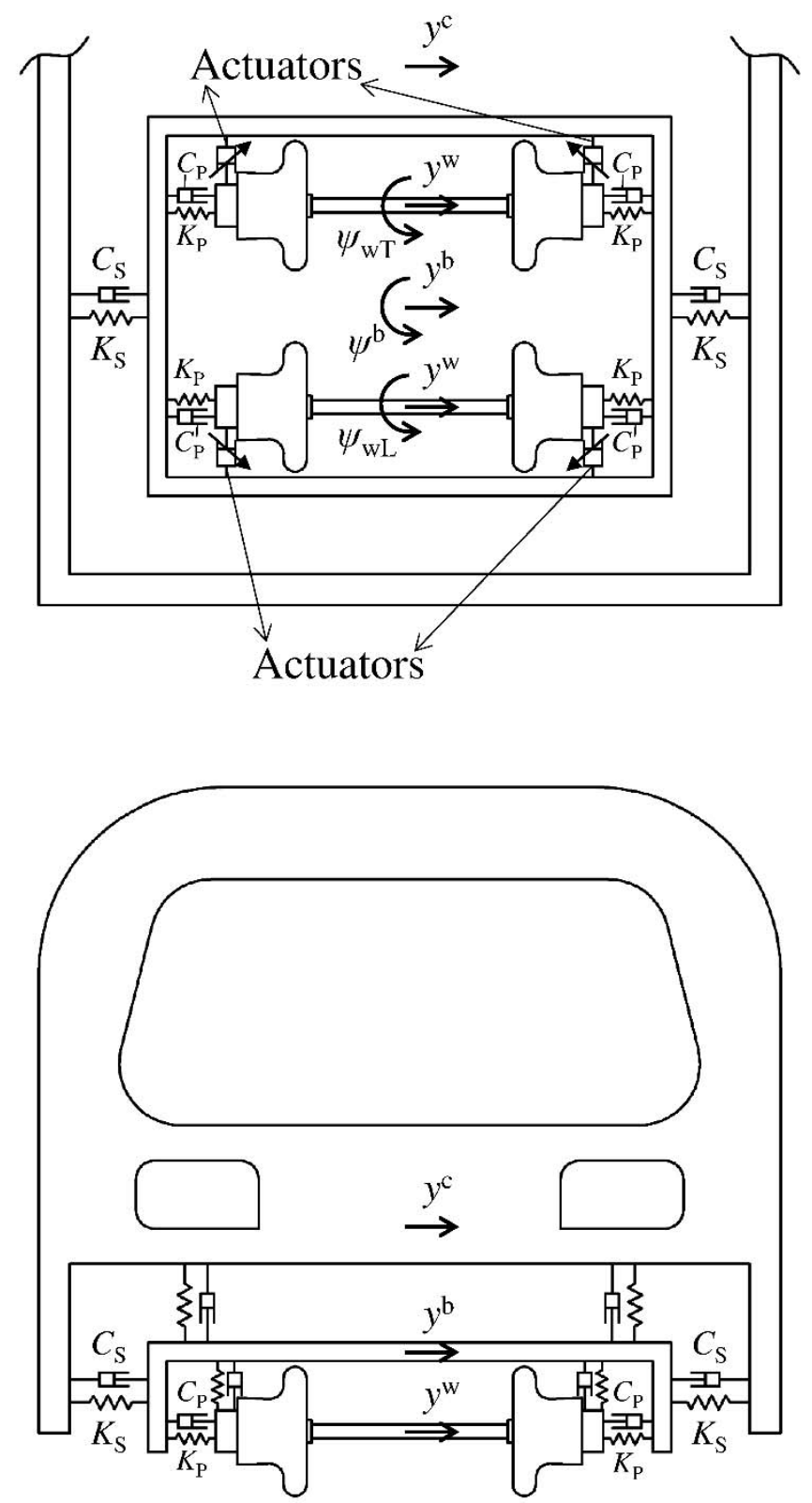

Fig. 1: Half-car railway vehicle model.

The Kalker's linear contact theory [19] is employed to attain the contact forces acting on wheel sets. It should be noted that the assumptions and theories used to develop the mathematical model of the vehicle such as rigid body elements, linear wheel profiles, two DOFs wheel sets and bogie frame as well as the Kalker's linear theory are sufficient for the purpose of suspension control design of high speed bogies, see e.g. $[13,14]$.

The equations of motions of the system are given as follows: 


$$
\begin{gathered}
m_{\mathrm{w}} \ddot{y}_{\mathrm{wL}}+\left(\frac{2 f_{22}}{V_{\mathrm{s}}}+C_{\mathrm{p}}\right) \dot{y}_{\mathrm{wL}}+K_{\mathrm{p}} y_{\mathrm{wL}}-2 f_{22} \psi_{\mathrm{wL}}-C_{\mathrm{p}} \dot{y}_{\mathrm{b}}-K_{\mathrm{p}} y_{\mathrm{b}} \\
-C_{\mathrm{p}} L_{\mathrm{v}} \dot{\psi}_{\mathrm{b}}-K_{\mathrm{p}} L_{\mathrm{v}} \psi_{\mathrm{b}}=m_{\mathrm{w}}\left(\frac{V_{s}^{2}}{R_{\mathrm{L}}}-g \theta_{\mathrm{cL}}\right), \\
I_{\mathrm{w}} \ddot{\psi}_{\mathrm{wL}}+\frac{2 f_{11} L_{\mathrm{g}}^{2}}{V_{\mathrm{s}}} \dot{\psi}_{\mathrm{wL}}+\frac{2 f_{11} \lambda L_{\mathrm{g}}}{r_{0}} y_{\mathrm{wL}}=\frac{2 f_{11} L_{\mathrm{g}}^{2}}{R_{\mathrm{L}}}+\frac{2 f_{11} \lambda L_{\mathrm{g}}}{r_{0}} y_{\mathrm{tL}}+T_{\mathrm{L}}^{\text {Act }}, \\
m_{\mathrm{w}} \ddot{y}_{\mathrm{wT}}+\left(\frac{2 f_{22}}{V_{\mathrm{s}}}+C_{\mathrm{p}}\right) \dot{y}_{\mathrm{wT}}+K_{\mathrm{p}} y_{\mathrm{wT}}-2 f_{22} \psi_{\mathrm{wT}}-C_{\mathrm{p}} \dot{y}_{\mathrm{b}}-K_{\mathrm{p}} y_{\mathrm{b}} \\
+C_{\mathrm{p}} L_{\mathrm{v}} \dot{\psi}_{\mathrm{b}}+K_{\mathrm{p}} L_{\mathrm{v}} \psi_{\mathrm{b}}=m_{\mathrm{w}}\left(\frac{V_{\mathrm{s}}^{2}}{R_{\mathrm{T}}}-g \theta_{\mathrm{cT}}\right), \\
I_{\mathrm{w}} \ddot{\psi}_{\mathrm{wT}}+\frac{2 f_{11} L_{\mathrm{g}}^{2}}{V_{\mathrm{s}}} \dot{\psi}_{\mathrm{wT}}+\frac{2 f_{11} \lambda L_{\mathrm{g}}}{r_{0}} y_{\mathrm{wT}}=\frac{2 f_{11} L_{\mathrm{g}}^{2}}{R_{\mathrm{T}}}+\frac{2 f_{11} \lambda L_{\mathrm{g}}}{r_{0}} y_{\mathrm{tT}}+T_{\mathrm{T}}^{\text {Act }}, \\
m_{\mathrm{b}} \ddot{y}_{\mathrm{b}}+\left(2 C_{\mathrm{p}}+C_{\mathrm{s}}\right) \dot{y}_{\mathrm{b}}+\left(2 K_{\mathrm{p}}+K_{\mathrm{s}}\right) y_{\mathrm{b}}-C_{\mathrm{p}} \dot{y}_{\mathrm{wL}}-K_{\mathrm{p}} y_{\mathrm{wL}}-C_{\mathrm{p}} \dot{y}_{\mathrm{wT}}-K_{\mathrm{p}} y_{\mathrm{wT}} \\
-C_{\mathrm{s}} \dot{y}_{\mathrm{v}}-K_{\mathrm{s}} y_{\mathrm{v}}=m_{\mathrm{b}} V_{\mathrm{s}}^{2}\left(\frac{1}{2 R_{\mathrm{L}}}+\frac{1}{2 R_{\mathrm{T}}}\right)-m_{\mathrm{b}} g\left(\frac{\theta_{\mathrm{cL}}}{2}+\frac{\theta_{\mathrm{cT}}}{2}\right), \\
m_{\mathrm{v}} \ddot{y}_{\mathrm{v}}+C_{\mathrm{s}} \dot{y}_{\mathrm{v}}+K_{\mathrm{s}} y_{\mathrm{v}}-C_{\mathrm{s}} \dot{y}_{\mathrm{b}}-K_{\mathrm{s}} y_{\mathrm{b}}=m_{\mathrm{v}} V_{\mathrm{s}}^{2}\left(\frac{1}{2 R_{\mathrm{L}}}+\frac{1}{2 R_{\mathrm{T}}}\right)-m_{\mathrm{v}} g\left(\frac{\theta_{\mathrm{cL}}}{2}+\frac{\theta_{\mathrm{cT}}}{2}\right) \\
2 L_{\mathrm{v}}^{2} C_{\mathrm{p}} \dot{\psi}_{\mathrm{b}}+2 L_{\mathrm{v}}^{2} K_{\mathrm{p}} \psi_{\mathrm{b}}-L_{\mathrm{v}} C_{\mathrm{p}} \dot{y}_{\mathrm{wL}}+L_{\mathrm{v}} C_{\mathrm{p}} \dot{y}_{\mathrm{wT}}-L_{\mathrm{v}} K_{\mathrm{p}} y_{\mathrm{wL}}+L_{\mathrm{v}} K_{\mathrm{p}} y_{\mathrm{wT}}=-\left(T_{\mathrm{L}}^{A c t}+T_{\mathrm{T}}^{\text {Act }}\right),
\end{gathered}
$$

The subscripts $\mathrm{L}$ and $\mathrm{T}$ denote leading and trailing wheel sets. Rest of the parameters and the corresponding values are introduced in Table 1. The system equations of motion described by Eqs. (17) are represented in the state space form as follows:

$$
\dot{\mathbf{x}}=\mathrm{A} \mathbf{x}+\mathrm{Bu}+\Gamma \mathbf{w}
$$

here,

$$
\begin{aligned}
\mathbf{x} & =\left[\begin{array}{llllllllllllll}
\dot{y}_{\mathrm{wL}} & y_{\mathrm{wL}} & \dot{\psi}_{\mathrm{wL}} & \psi_{\mathrm{wL}} & \dot{y}_{\mathrm{wT}} & y_{\mathrm{wT}} & \dot{\psi}_{\mathrm{wT}} & \psi_{\mathrm{wT}} & \dot{y}_{\mathrm{b}} & y_{\mathrm{b}} & \dot{\psi}_{\mathrm{b}} & \psi_{\mathrm{b}} & \dot{y}_{\mathrm{v}} & y_{\mathrm{v}}
\end{array}\right]^{\mathrm{T}}, \\
\mathbf{u} & =\left[\begin{array}{lllllll}
T_{\mathrm{L}}^{\text {Act }} & T_{\mathrm{T}}^{\text {Act }}
\end{array}\right]^{\mathrm{T}}, \\
\mathbf{w} & =\left[\begin{array}{llllll}
1 / R_{\mathrm{L}} & \theta_{\mathrm{cL}} & y_{\mathrm{tL}} & 1 / R_{\mathrm{T}} & \theta_{\mathrm{cT}} & y_{\mathrm{tT}}
\end{array}\right]^{\mathrm{T}} .
\end{aligned}
$$

Vectors $\mathbf{x}, \mathbf{u}$, and $\mathbf{w}$ represent the system state vector, the two control torques, and inputs from the track, respectively. The explicit expressions for matrices $\mathrm{A}, \mathrm{B}$, and $\Gamma$ are given in the appendix. 
Table 1: Vehicle's structural parameters and variables.

\begin{tabular}{|c|c|}
\hline Parameter & Description and values \\
\hline$C_{\mathrm{p}}, C_{\mathrm{s}}$ & Lateral primary damping $(37 \mathrm{kNs} / \mathrm{m})$ and lateral secondary damping $(12 \mathrm{kNs} / \mathrm{m})$ \\
\hline$f_{11}, f_{22}$ & Longitudinal and lateral creep coefficients (10 MN, $10 \mathrm{MN})$ \\
\hline$T^{\text {Act }}$ & Control force from actuator \\
\hline$g$ & Gravitational acceleration $\left(9.81 \mathrm{~m} / \mathrm{s}^{2}\right)$ \\
\hline$I_{\mathrm{b}}, I_{\mathrm{w}}$ & Bogie frame yaw inertia $\left(3200 \mathrm{~kg} \cdot \mathrm{m}^{2}\right)$ and wheel set yaw inertia $\left(766 \mathrm{~kg} \cdot \mathrm{m}^{2}\right)$ \\
\hline$K_{\mathrm{p}}, K_{\mathrm{s}}$ & Lateral primary stiffness $(511 \mathrm{kN} / \mathrm{m})$ and lateral secondary stiffness $(471 \mathrm{kN} / \mathrm{m})$ \\
\hline$L_{\mathrm{g}}$ & Half gauge of wheel set $(0.75 \mathrm{~m})$ \\
\hline$L_{\mathrm{v}}$ & Half spacing of axles $(1.225 \mathrm{~m})$ \\
\hline$m_{\mathrm{b}}, m_{\mathrm{v}}, m_{\mathrm{w}}$ & Bogie frame mass $(3447 \mathrm{~kg})$, vehicle mass $(34460 \mathrm{~kg})$, wheel set mass $(1376 \mathrm{~kg})$ \\
\hline$r_{0}$ & Wheel radius $(0.445 \mathrm{~m})$ \\
\hline$R$ & Radius of curvature of the track $(3500 \mathrm{~m})$ \\
\hline$V_{\mathrm{s}}$ & Vehicle speed $(300 \mathrm{~km} / \mathrm{h})$ \\
\hline$y \mathrm{~b}, y_{\mathrm{w}}, y_{\mathrm{v}}$ & Bogie frame, wheel set, and half-carbody lateral displacements \\
\hline$y_{\mathrm{t}}$ & Lateral random track irregularity \\
\hline$\theta_{\mathrm{c}}$ & Cant angle $(6 \cdot \pi / 180 \mathrm{rad})$ \\
\hline$\lambda$ & Wheel conicity $(0.3)$ \\
\hline$\psi_{\mathrm{b}}, \psi_{\mathrm{w}}$ & Yaw angle of bogie frame and wheel set \\
\hline
\end{tabular}

\section{Robust Control Design}

One of the key factors in railway operations (especially at high speeds) is running stability which is particularly important for safety and ride comfort. Therefore, the controller should first of all stabilize the wheel set motion. Active steering of the vehicle and excellent curving performance with a realistic control effort are also some of the design requirements. Furthermore, the controller has to be robust against parameter uncertainties in the wheel/rail contact patch. The $\mathrm{H}_{\infty}$ control design technique is one of the most well-known robust control design schemes. This method has been employed in [14] for robust control of a railway vehicle with independently rotating wheels. One of the targets here is to utilise the $\mathrm{H}_{\infty}$ scheme for robust control of a railway vehicle with solid axles.

In order to satisfy the abovementioned design requirements it is not necessary to control all the states of the system. A global sensitivity analysis on the wheel/rail contact properties with respect to the wheel set dynamics proved that the contact properties such as creepages, contact forces, and contact patch dimensions are mostly sensitive with respect to the wheel set lateral and yaw motions, see [20, 21]. The lateral wheel set motion should be below certain limit ( $8 \mathrm{~mm}$ in most of the cases) to avoid a flange contact. On the other hand, the wheel set yaw motion can significantly affect the contact forces. However, a study on optimization revealed that it is only necessary to minimize the wheel set lateral motion, see e.g. $[14,22]$. The same concept is followed here and the leading and trailing wheel set lateral motions (i.e. $y_{\mathrm{wL}}$ and $y_{\mathrm{wT}}$ ) are considered as the first set of two variables in the vehicle model output 
vector $(\mathbf{y})$. As part of the control design task and from practical point of view one should also expect an appropriate control effort. Consequently, the control torques acting on the leading and trailing wheel sets are also defined as the second set of two variables in $\mathbf{y}$. Furthermore, the dynamic response of the wheel set should also be part of the output vector $(\mathbf{y})$. This is done by considering practical accelerometers and angular velocity sensors to measure the lateral acceleration and yaw angular velocity of the leading and trailing wheel sets (i.e. $\ddot{y}_{\mathrm{wL}}, \ddot{y}_{\mathrm{wT}}, \dot{\psi}_{\mathrm{wL}}, \dot{\psi}_{\mathrm{wT}}$ ). Finally, the system output vector $\mathbf{y}$ is defined as follows:

$$
\mathbf{y}=\left[\begin{array}{l}
y_{1} \\
y_{2}
\end{array}\right]=\left[\begin{array}{llllllll}
y_{\mathrm{wL}} & y_{\mathrm{wT}} & T_{\mathrm{L}}^{\mathrm{Crrl}} & T_{\mathrm{T}}^{\mathrm{Ctrl}} & \ddot{y}_{\mathrm{wL}} & \dot{\psi}_{\mathrm{wL}} & \ddot{y}_{\mathrm{wT}} & \dot{\psi}_{\mathrm{wT}}
\end{array}\right]^{\mathrm{T}}
$$

Here $T^{\mathrm{Ctrl}}$ is the ideal control effort (with no actuator dynamics taken into account). Indeed, an ideal actuator is considered during the control design process and it is assumed that the actuator output is equal to the ideal control command, i.e. $T^{\text {Act }}=T^{\text {Ctrl }}$. The actuator dynamics and the respective control torque $T^{\text {Act }}$ will be considered later on to check the performance of the designed controller on the dynamics behaviour of the vehicle when the actuator dynamics is taken into account.

The input vector for the control design problem $\left(\mathbf{u}_{\text {in }}\right)$ is defined as:

$$
\mathbf{u}_{\mathrm{in}}=\left[\begin{array}{l}
\mathrm{u}_{1} \\
\mathrm{u}_{2}
\end{array}\right]=\left[\begin{array}{lllllll}
\ddot{y}_{\mathrm{wL}}^{\mathrm{n}} & \dot{\psi}_{\mathrm{wL}}^{\mathrm{n}} & \ddot{y}_{\mathrm{wT}}^{\mathrm{n}} & \dot{\psi}_{\mathrm{wT}}^{\mathrm{n}} & \mathbf{w}^{\mathrm{T}} & T_{\mathrm{L}}^{\mathrm{C}} \mathrm{trl} & T_{\mathrm{T}}^{\mathrm{C}+r 1}
\end{array}\right]^{\mathrm{T}},
$$

where, the superscript $\mathrm{n}$ indicates the sensor noise associated with the respective measured parameters. For the purpose of control design, the state space equations of the system (Eq. (8)) should be modified based on the system output and control input vectors defined by Eqs. $(9,10)$ to attain the augmented state space form of the system equations:

$$
\begin{gathered}
\dot{\mathbf{x}}=\mathrm{A} \mathbf{x}+\left[\begin{array}{ll}
\mathrm{B}_{1} & \mathrm{~B}_{2}
\end{array}\right] \mathbf{u}_{\text {in }} \\
\mathbf{y}=\left[\begin{array}{l}
\mathrm{C}_{1} \\
\mathrm{C}_{2}
\end{array}\right] \mathbf{x}+\left[\begin{array}{ll}
\mathrm{D}_{11} & \mathrm{D}_{12} \\
\mathrm{D}_{21} & \mathrm{D}_{22}
\end{array}\right] \mathbf{u}_{\text {in }}
\end{gathered}
$$

Matrices $\mathrm{B}_{1}, \mathrm{~B}_{2}, \mathrm{C}_{1}, \mathrm{C}_{2}, \mathrm{D}_{11}, \mathrm{D}_{12}, \mathrm{D}_{21}$, and $\mathrm{D}_{22}$ are defined in the appendix. The MATLAB-Simulink block diagram of the system used for the control design is shown in Fig. 2.

The matrices $\mathrm{W}_{\mathrm{iR}}$ and $\mathrm{W}_{\mathrm{iD}}$ are defined as the input weighting matrix on a straight track with irregularities and a track with deterministic inputs, respectively. The matrix $\left(\mathrm{W}_{\mathrm{fy}}\right)$ is a dynamic weighting factor used to shape the frequency response of each of the wheel sets' lateral displacement and provide stability once track irregularity exist which is defined as:

$$
\mathrm{W}_{\mathrm{fy}}=k_{\mathrm{fy}} \operatorname{diag}\left(\frac{s^{2}+2 \zeta_{y \alpha} \omega_{y \alpha} s+\omega_{y \alpha}^{2}}{s^{2}+2 \zeta_{y \beta} \omega_{y \beta} s+\omega_{y \beta}^{2}}\right)_{2 \times 2}
$$




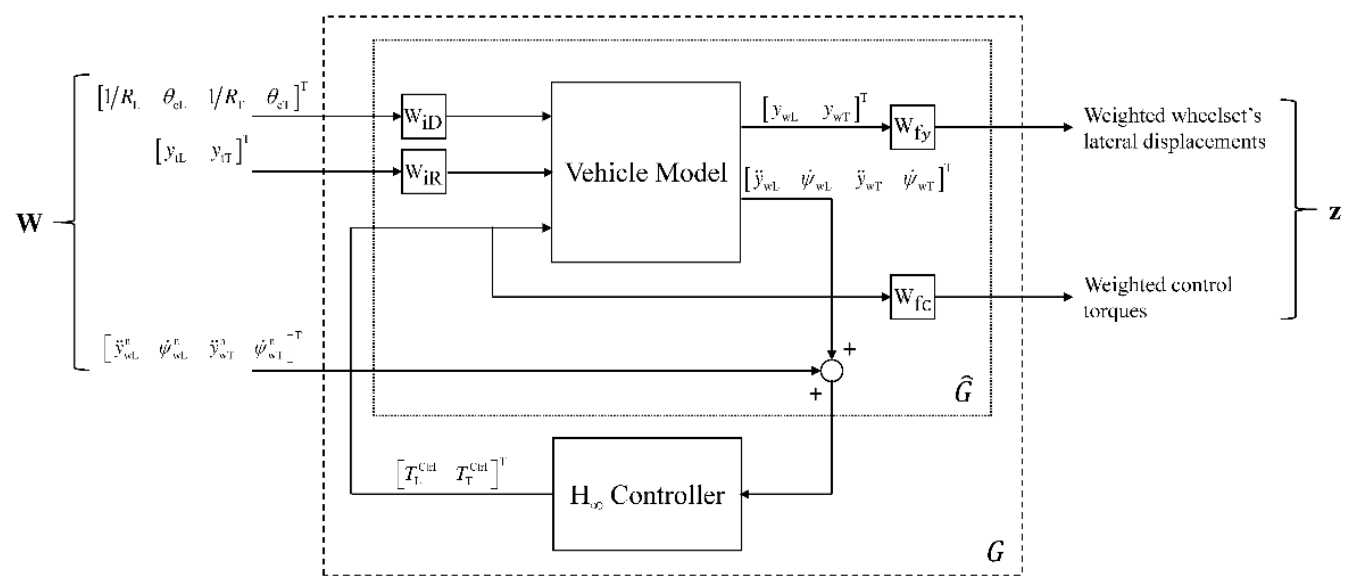

Figure 2: Block diagram of the robust control design.

In a similar manner the matrix $\left(\mathrm{W}_{\mathrm{fC}}\right)$ is a dynamic weighting factor used to account the actuator dynamics and capacity constraints and is defined as:

$$
\mathrm{W}_{\mathrm{fc}}=k_{\mathrm{Tc}} \operatorname{diag}\left(\frac{s^{2}+2 \zeta_{\mathrm{c} \alpha} \omega_{\mathrm{c} \alpha} s+\omega_{\mathrm{c} \alpha}^{2}}{s^{2}+2 \zeta_{\mathrm{c} \beta} \omega_{\mathrm{c} \beta} s+\omega_{\mathrm{c} \beta}^{2}}\right)_{2 \times 2}
$$

It should be noted that the weighting matrices $\left(\mathrm{W}_{\mathrm{iR}}, \mathrm{W}_{\mathrm{iD}}, \mathrm{W}_{\mathrm{fy}}\right.$, and $\left.\mathrm{W}_{\mathrm{fC}}\right)$ shown in block diagram of Fig. 2 are only introduced for the controller design purpose and are not generally part of the system state equations. Indeed, these matrices have to be tuned during the control design process to give an appropriate controller. Once the controller is designed, the weighting matrices could be removed and the controller effects on the vehicle dynamics performance can be studied.

The target of control design is to stabilize the closed-loop system $(G)$ and attenuate the effects of the track inputs on the dynamic output of the system. This is done by minimizing the $\mathrm{H}_{\infty}$ norm of the transfer function between the track inputs and the system outputs (i.e. min $\|\hat{G}\|_{\infty}$ ). The track inputs cause uncertainties in the wheel/rail contact parameters and are identified by the vector $\mathbf{w}$ which includes the deterministic operational scenario $\left(1 / R_{\mathrm{L}}, \theta_{\mathrm{cL}}, 1 / R_{\mathrm{T}}, \theta_{\mathrm{cT}}\right)$ and measured track irregularities $\left(y_{\mathrm{tL}}, y_{\mathrm{tT}}\right)$.

The MATLAB robust control design toolbox " $\mu$-tools" is employed to carry out the $\mathrm{H}_{\infty}$ control design. The robustness of the proposed controller is checked via $\mu$-synthesis against variations in the contact parameters. In particular, the longitudinal and lateral creep coefficients $\left(f_{11}, f_{22}\right)$ and wheel conicity $\lambda$.

The vehicle performance is optimized by tuning the controller parameters and weighting matrices. Final values are given in Table 2 . 
Table 2: Parameters of the weighting matrices.

\begin{tabular}{lr}
\hline Parameter & Definition and value \\
\hline$K_{\mathrm{fy}}$ & Coefficient of the weighting matrices on the wheel set lateral displacements (sqrt(2.5)) \\
\hline$K_{\mathrm{Tc}}$ & Coefficient of the weighting matrices on the control torques $(5 \mathrm{e}-6)$ \\
\hline $\mathrm{W}_{\mathrm{iD}}$ & Input weighting matrix on the deterministic track input $\left(0.5^{*} \mathrm{I}_{2 \times 2}\right)$ \\
\hline $\mathrm{W}_{\mathrm{iR}}$ & Input weighting matrix on the random track input $\left(0.5^{*} \mathrm{I} \times 4\right)$ \\
\hline$\omega_{y \alpha}, \omega_{y \beta}$ & Frequencies of the dynamic weighting on the wheel set lateral displacements $(1,100 \mathrm{~Hz})$ \\
\hline$\zeta_{y \alpha}, \zeta_{y \beta}$ & Damping ratios of the dynamic weighting on the wheel set lateral displacements $(1,1)$ \\
\hline$\omega_{\mathrm{c} \alpha}, \omega_{\mathrm{c} \beta}$ & Frequencies of the dynamic weighting on the control torques $(1,100 \mathrm{~Hz})$ \\
\hline$\zeta_{\mathrm{c} \alpha}, \zeta_{\mathrm{c} \beta}$ & Damping ratios of the dynamic weighting on the control torques $(1,1)$ \\
\hline
\end{tabular}

\section{Compensation of Actuator Dynamics}

Although the effect of actuator dynamics has been taken into account within the dynamic weighting matrices, the actuator model has not been considered in the computer simulations carried out in [14]. The controller output represents the ideal control force and in practice actuators should be utilised to apply the control force to the vehicle. Due to the actuator dynamics in the vehicle suspension applications a delayed response from the ideal control force to the actuator output is inevitable. The actuator time delay can induce negative damping and make the system unstable. Therefore, special attention has to be paid to the actuator dynamics compensation to make the actuator output as close as possible to the ideal control force. In this section, first the actuator mathematical model used in this study is introduced and then a method for actuator dynamics compensation is proposed.

\subsection{Actuator Model}

Ball-screw electromechanical actuators are one of the most widely-used elements in active control of vehicles and are applied to control the wheel set lateral displacements in this study. This type of actuators constitutes of an electric motor and a ball-screw mechanism which converts the motor torque into a linear force as shown in Fig. 3.

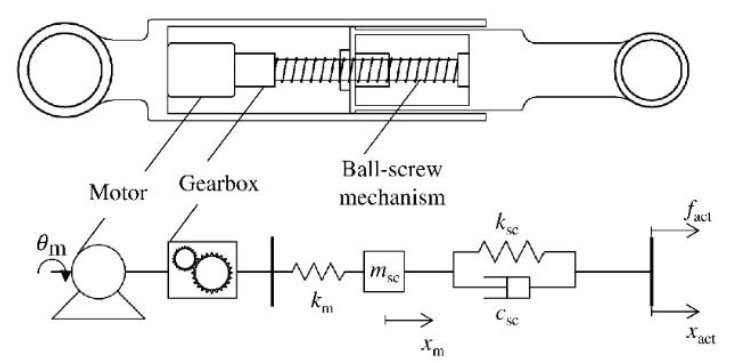

Figure 3: The ball-screw actuator and its equivalent mechanical model. 
The mathematical model of the ball-screw actuator is described as [23, 24]:

$$
\left\{\begin{array}{c}
\dot{i}_{a}=-\frac{r_{\mathrm{arm}}}{l_{\mathrm{arm}}} i_{a}-\frac{k_{\mathrm{e}}}{l_{\mathrm{arm}}} \dot{\theta}_{\mathrm{m}}+\frac{1}{l_{\mathrm{arm}}} v_{a} \\
\ddot{\theta}_{m}=\frac{k_{\mathrm{t}}}{J_{\mathrm{m}}} i_{a}-\frac{c_{\mathrm{m}}}{J_{\mathrm{m}}} \dot{\theta}_{\mathrm{m}}-\frac{k_{\mathrm{m}} n^{2}}{J_{\mathrm{m}}} \theta_{\mathrm{m}}+\frac{k_{\mathrm{m}} n}{J_{\mathrm{m}}} x_{\mathrm{m}} \\
\ddot{x}_{m}=\frac{k_{\mathrm{m}} n}{m_{\mathrm{sc}}} \theta_{\mathrm{m}}-\frac{k_{\mathrm{m}}+k_{\mathrm{sc}}}{m_{\mathrm{sc}}} x_{\mathrm{m}}-\frac{c_{\mathrm{sc}}}{m_{\mathrm{sc}}} \dot{x}_{\mathrm{m}}+\frac{k_{\mathrm{sc}}}{m_{\mathrm{sc}}} x_{\mathrm{Act}}+\frac{c_{\mathrm{sc}}}{m_{\mathrm{sc}}} \dot{x}_{\mathrm{Act}} \\
F_{\mathrm{Act}}=k_{\mathrm{sc}} x_{\mathrm{m}}+c_{\mathrm{sc}} \dot{x}_{\mathrm{m}}-k_{\mathrm{sc}} x_{\mathrm{Act}}-c_{\mathrm{sc}} \dot{x}_{\mathrm{Act}}
\end{array}\right.
$$

Here, $x_{\text {Act }}$ and $\dot{x}_{\text {Act }}$ denote the relative displacement and relative velocity of the actuator's ends which can be directly measured from the vehicle model. The rest of the actuator parameters in Eq. (15) are defined in Table 3.

Table 3: The ball-screw electromechanical actuator parameters [13].

\begin{tabular}{lr}
\hline Parameter & Definition \\
\hline$x_{\mathrm{Act}}$ & Relative displacement of the actuator \\
\hline$x_{\mathrm{m}}$ & Displacement of the ball-screw \\
\hline$\theta_{\mathrm{m}}$ & Rotation angle of the motor \\
\hline$F_{\mathrm{Act}}$ & Actuator force \\
\hline$v_{\mathrm{a}, i_{\mathrm{a}}}$ & Voltage and current of the motor \\
\hline$m_{\mathrm{sc}}$ & Screw mass $(2 \mathrm{~kg})$ \\
\hline$k_{\mathrm{sc}}$ & Screw stiffness $(1.131 \mathrm{e} 7 \mathrm{~N} / \mathrm{m})$ \\
\hline$c_{\mathrm{sc}}$ & Screw damping $(7540.7 \mathrm{Ns} / \mathrm{m})$ \\
\hline$k_{\mathrm{m}}$ & Motor series stiffness $(1 \mathrm{e} 7 \mathrm{~N} / \mathrm{m})$ \\
\hline$c_{\mathrm{m}}$ & Motor damping $(0.0084 \mathrm{Nm} / \mathrm{rad} . \mathrm{s})$ \\
\hline$J_{\mathrm{m}}$ & Motor Inertia $\left(0.00115 \mathrm{kgm}{ }^{2}\right)$ \\
\hline$n$ & Screw pitch $(1 / 87)$ \\
\hline$k_{\mathrm{t}}$ & Motor torque constant $(0.537 \mathrm{Nm} / \mathrm{A})$ \\
\hline$k_{\mathrm{e}}$ & Motor back-emf gain $(0.435 \mathrm{~V} / \mathrm{rad} / \mathrm{s})$ \\
\hline$l_{\mathrm{arm}}$ & Winding inductance $(0.904 \mathrm{mH})$ \\
\hline$r_{\mathrm{arm}}$ & Winding resistance $(0.112 \Omega)$ \\
\hline
\end{tabular}

\subsection{Compensation Technique}

In practice, a local controller (in this case PI controller) is often tuned to minimize the error between the desired control command and the actuator output. In this study, a compensation technique is proposed in addition to the PI controller to further compensate the actuator dynamics.

The actuator time delay can be considered as a constant in many applications such as earthquake engineering, see e.g. [25]. However, in the vehicle dynamics and suspension system applications the actuator time delay is dynamic and hence frequency dependent. In order to alleviate the actuator dynamic 
effects on the vehicle performance it is necessary to estimate the time delay online and use an appropriate dynamics compensation procedure.

To estimate the delay, the control command (input to the actuator from controller) and the actuator's output are predicted using the polynomial extrapolations as shown in Fig. 3. The extrapolation can be applied using polynomials with different orders. The resulting amplitude magnification and phase for different prediction methods depend on the polynomial order and frequency, see e.g. $[25,26]$. For the actuator model in question, the second-order polynomials showed a satisfactory compensation efficiency and are used in this paper. It should be noted that the number of points considered for prediction the control command and actuator's output using the second-order polynomials are optimised to yield higher efficiency.

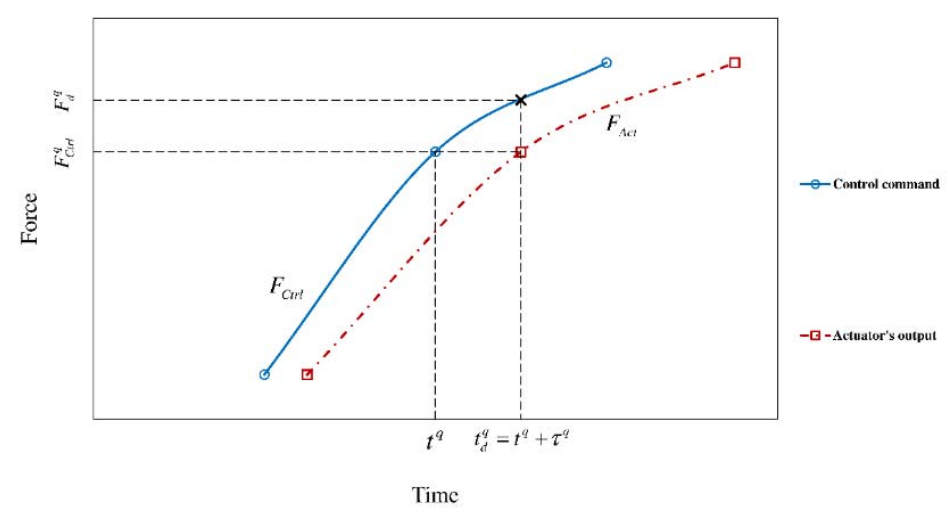

Figure 4: Fitted curves on control command and the actuator's output.

At time $q$ the actuator output $\left(F_{\text {Act }}\right)$ is estimated as a second-order function of time:

$$
F_{\mathrm{Act}}^{q}=a_{\mathrm{A}}^{q} t^{2}+b_{\mathrm{A}}^{q} t+c_{\mathrm{A}}^{q}
$$

The control command at the time $q$ is $F_{\mathrm{Ctrl}}^{q}$. By taking $F_{\mathrm{Act}}^{q}=F_{\mathrm{Ctrl}}^{q}$ and solving Eq. (16), the desired time $t_{\mathrm{d}}^{q}$ in which the actuator's output is equal to the control command $F_{\mathrm{Ctrl}}^{q}$ is determined as follows:

$$
t_{\mathrm{d}}^{q}=\frac{-b_{\mathrm{A}}^{q} \pm \sqrt{\left(b_{A}^{q}\right)^{2}-4 a_{\mathrm{A}}^{q}\left(c_{\mathrm{A}}^{q}-F_{\mathrm{Ctrl}}^{q}\right)}}{2 a_{\mathrm{A}}^{q}}
$$

where, the root closer to the current simulation time $t^{q}$ is chosen as $t_{\mathrm{d}}^{q}$. The time delay at the time $q$ is then equal to $\tau^{q}=t_{\mathrm{d}}^{q}-t^{q}$.

Therefore, the desired time at $q\left(t_{\mathrm{d}}^{q}\right)$ is calculated using Eq. (17) and is known. Since, the integration time step $(\Delta t=1 \mathrm{e}-5 \mathrm{~s})$ is smaller than the time delay (i.e. $\Delta t<<\tau)$, it is assumed that the time delay remains constant between two time steps. Consequently, the control command for the next integration step $q_{+1}$ 
(i.e. $\left.F_{\mathrm{Crl}}^{q_{+1}}\left(t^{q_{+1}}\right)\right)$ can be found by evaluating a polynomial extrapolation of the control command signal at time $t^{q_{+1}}=t_{\mathrm{d}}^{q}+\Delta t$.

The schematic diagram of the compensation procedure is shown in Fig. 5. Using the control command from the $\mathrm{H}_{\infty}$ controller $\left(F_{\mathrm{Ctrl}}\right)$ and measured actuator output $\left(F_{\mathrm{Act}}\right)$, the compensation block estimates the desired time at step $q\left(t_{\mathrm{d}}^{q}\right)$ and accordingly predicts the desired control signal for the next time step, i.e. $F_{\mathrm{Crl}}^{q_{+1}}\left(t^{q_{+1}}\right)$. This is done with the aid of second order polynomial extrapolation using polyfit block in MATLAB SIMULINK. The modified control command is then applied to the actuators. As aforementioned, the number of points used to predict the control command are optimised to attain the best performance. In addition, a PI controller is also tuned to further compensate the actuator dynamics and reduce the error between the control command and actuator's output.

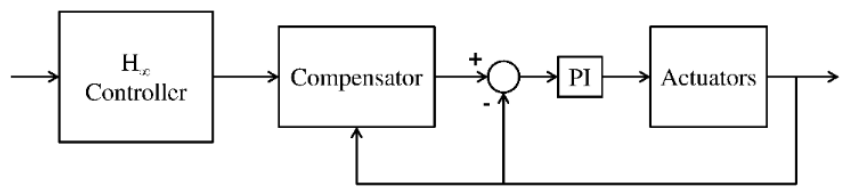

Figure 5: Block diagram of the compensation technique.

\section{Results}

The simulation results associated with the half-car railway vehicle model shown in Fig. 1 as well as a full scale one-car railway vehicle with nonlinear wheel and rail profiles are scrutinised in this section.

\subsection{Results of the half-car vehicle model}

The radius of curvature and cant angle for the considered operational scenario are shown in Fig. 6.
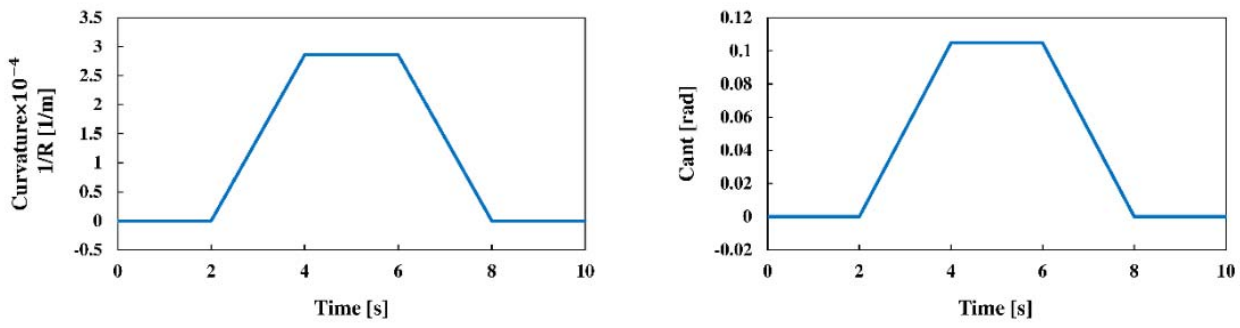

Figure 6: Operational scenario for the simulations.

The running speed is $V_{\mathrm{s}}=300 \mathrm{~km} / \mathrm{h}$. To check the controller performance in disturbance rejection, real measurement data from the Swedish Transport Administration (Trafikverket) are applied to the model as the lateral track irregularities. 
The power spectral density (PSD) of lateral displacement of the leading axle for the ideal case (No Act Dyn) and the two cases with actuator dynamics: no compensation and with compensation are demonstrated in Fig. 7. It should be noted that the vertical axis is in the logarithmic scale and "No Act Dyn" corresponds the case that the control demand (from the controller) is directly applied to the vehicle model.

It can be seen that the compensation technique appropriately compensates the actuator dynamics inasmuch as the system response for the case with no actuator dynamics is close to the case with compensation technique.

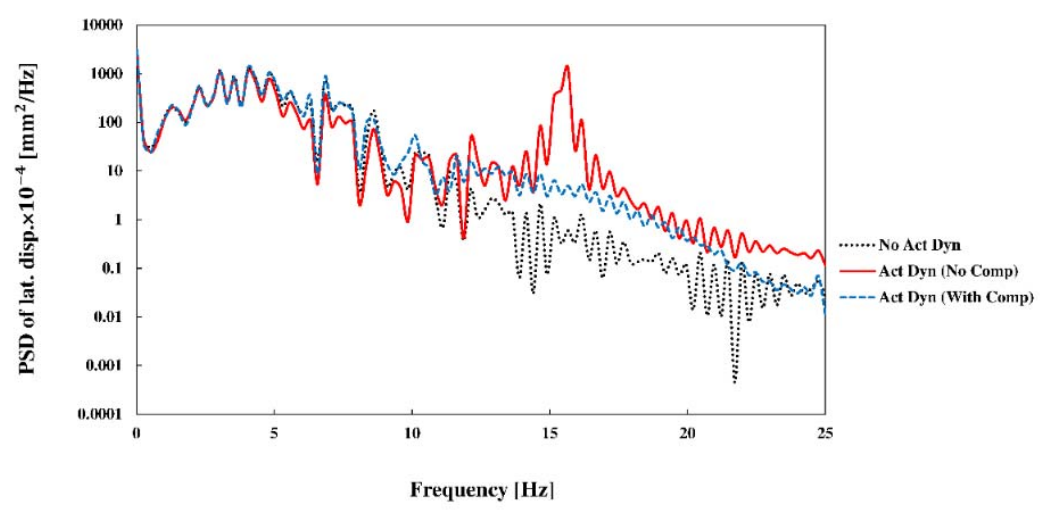

Figure 7: PSD of lateral displacement of the leading axle for the ideal case (No Act Dyn) and the two cases with actuator dynamics: with and without compensation.

The longitudinal contact forces acting on the leading and trailing wheel sets are plotted in Fig. 8. Since the values are relatively small and close to one another, it can be deduced that the controller provides excellent curving performance.

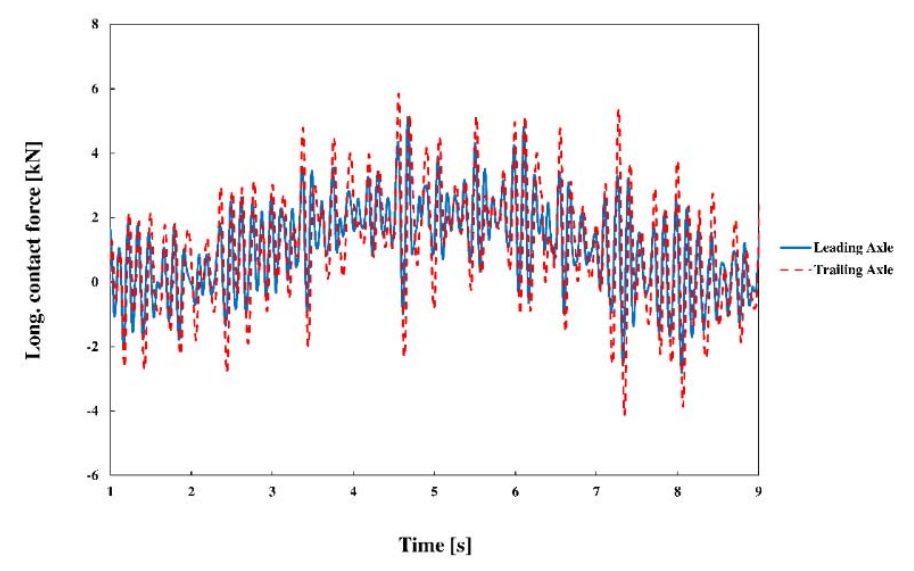

Figure 8: Longitudinal contact force of the front and rear wheel sets. 
The PSD of the control forces are plotted in Fig. 9. The vertical axis is in the logarithmic scale. It can be seen that a similar pattern to the lateral displacement of the leading axle is followed here. The proposed compensation technique properly reduced the actuator dynamics effects and the actuator output is close to the ideal control command when the compensation technique is used. The origin of the peaks in the graphs corresponding to the case "Act Dyn (No Comp)" is the actuator dynamics and respective effects on the dynamics behaviour of the vehicle. From Figs. 7 and 9 it can be seen that the vehicle response is sensitive with respect to the exciting frequencies around $16 \mathrm{~Hz}$ when the actuator dynamics is not compensated.

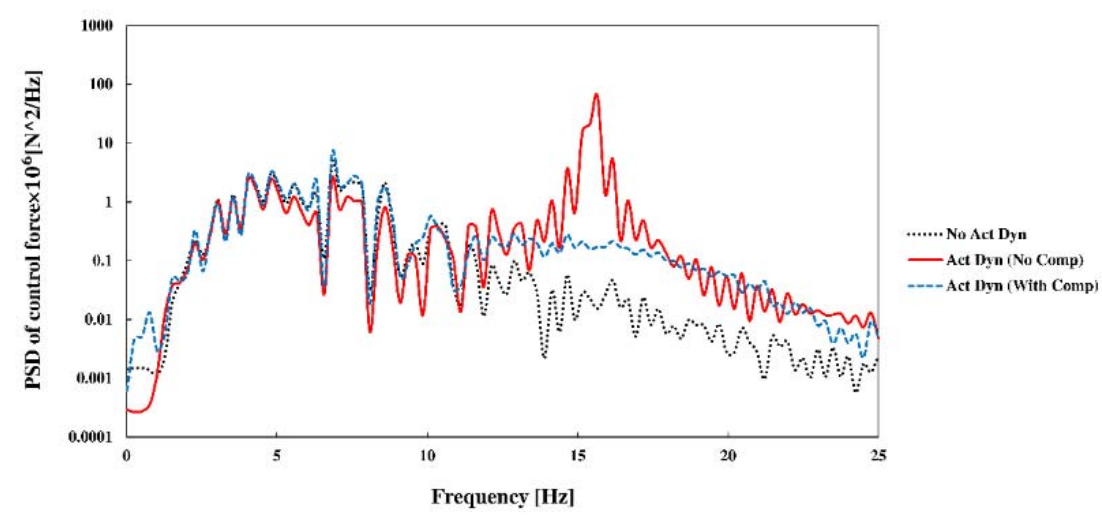

Figure 9: Control Force PSD for the Ideal case (No Actuator Dyn) and the two cases with Actuator Dynamics: with and without compensation.

To compare the energy consumed by the actuator in the case of with and without using the compensation technique, the PSD of the actuator's input voltage as well as the actuator's output force-input velocity are shown in Fig. 10 and Fig. 11, respectively. Note that the vertical axis in Fig. 10 is in the logarithmic scale.

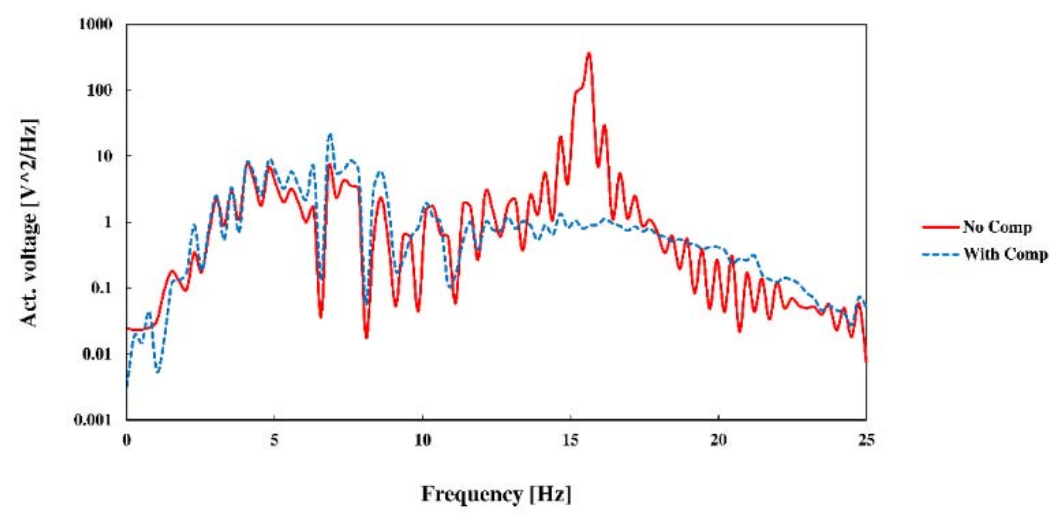

Figure 10: PSD of the actuator's input voltage for the case of with and without compensation.

It can be seen that the proposed compensation technique requires less input voltage. Furthermore, the area covered by the actuator's output force-input velocity is much less than the case without 
compensation. Consequently, the proposed technique consumes less energy in comparison with the case with no compensation which is beneficial.

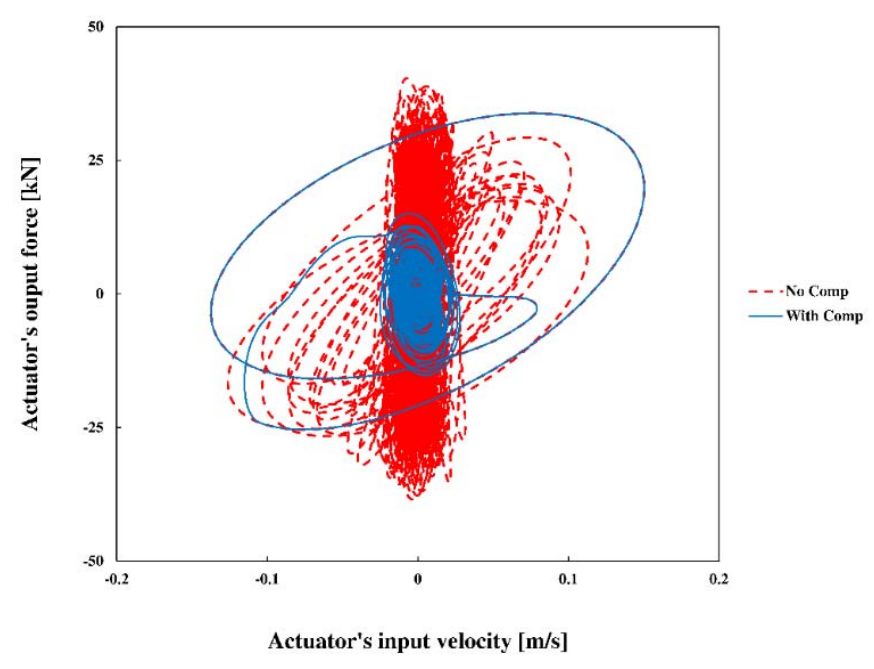

Figure 11: Actuator's force-velocity graph.

From the simulation results obtained in this section for a railway vehicle with linear wheel and rail profiles, it can be deduced that the controller yields a satisfactory performance when operating at $V \mathrm{~s}=$ $300 \mathrm{~km} / \mathrm{h}$ on the specified track with realistic irregularities. It should be noted that although the compensation technique improved the performance, using the actuator without compensation also lead to system stability for the vehicle model in question. In the next section the target is to explore the controller and compensation technique performance for a railway vehicle model with nonlinear wheel and rail profiles.

\subsection{Simulations on a full scale one-car railway vehicle}

In this section, the performance of the proposed controller is tested on a one-car railway vehicle model with 50 degrees of freedom developed in the multibody dynamics software SIMPACK, see Fig. 12. The structural parameters used to develop the vehicle model are in-service data provided by the Bombardier Transportation, Västerås, Sweden. The wheel and rail profiles are created based on the nominal S1002 and $60 \mathrm{E} 1$ profiles, respectively. Two ball-screw electromechanical actuators are attached to each wheel sets to apply the control torque. Accelerometers and angular velocity sensors are considered on each wheel set in the SIMPACK vehicle model to carry out the required measurements. On the other hand, the actuator model and block structures required to calculate the control torques are implemented in MATLAB/SIMULINK. Therefore, SIMAT module is used to perform the simulations in the SIMPACK/SIMULINK co-simulation interface. More details on the vehicle model and co-simulation process can be found in $[6,21]$. 


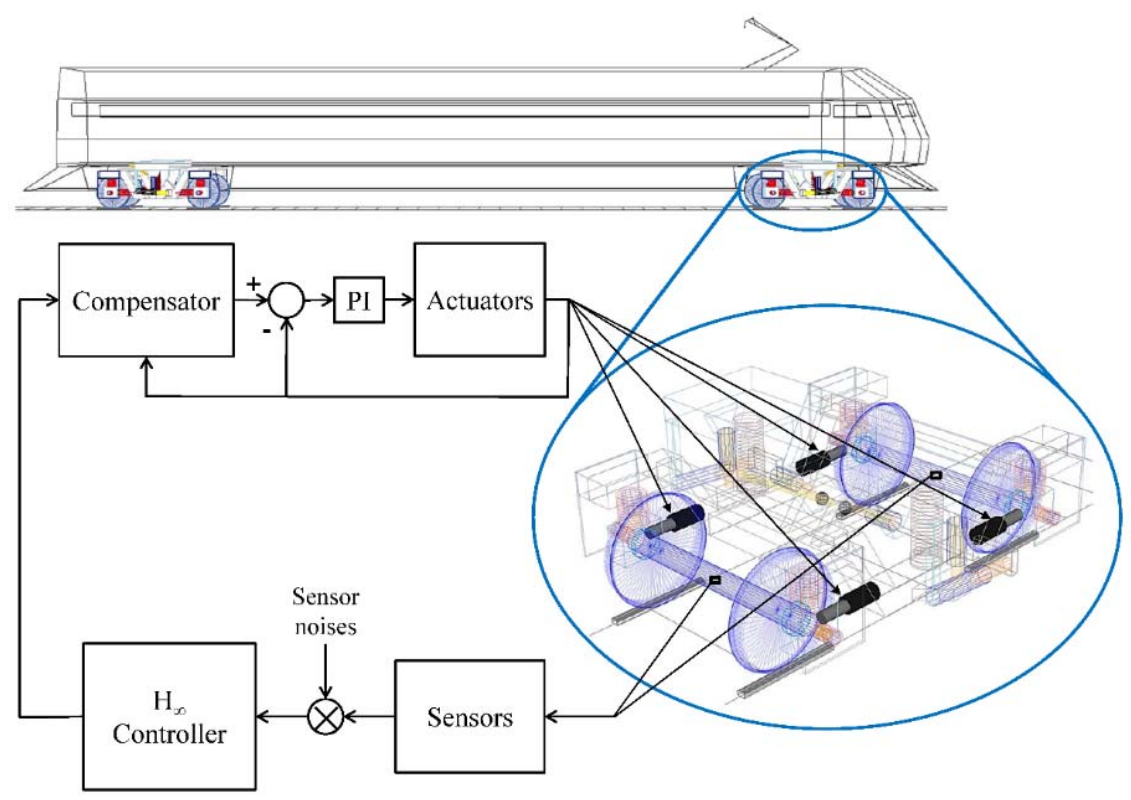

Figure 12: Application of the proposed controller for a full scale one-car railway vehicle model.

Measurement data from Swedish Transport Administration are used as the track irregularities in the lateral direction.

The lateral displacement of the leading axle is plotted and compared in Fig. 13 for the case of passive control and the proposed robust controller. It can be seen that a significant improvement can be achieved using the active control technology. It should be noted that the vehicle runs at $V_{\mathrm{s}}=300 \mathrm{~km} / \mathrm{h}$ and the passive case corresponds to the in-service data from Bombardier Transportation, Västerås, Sweden.

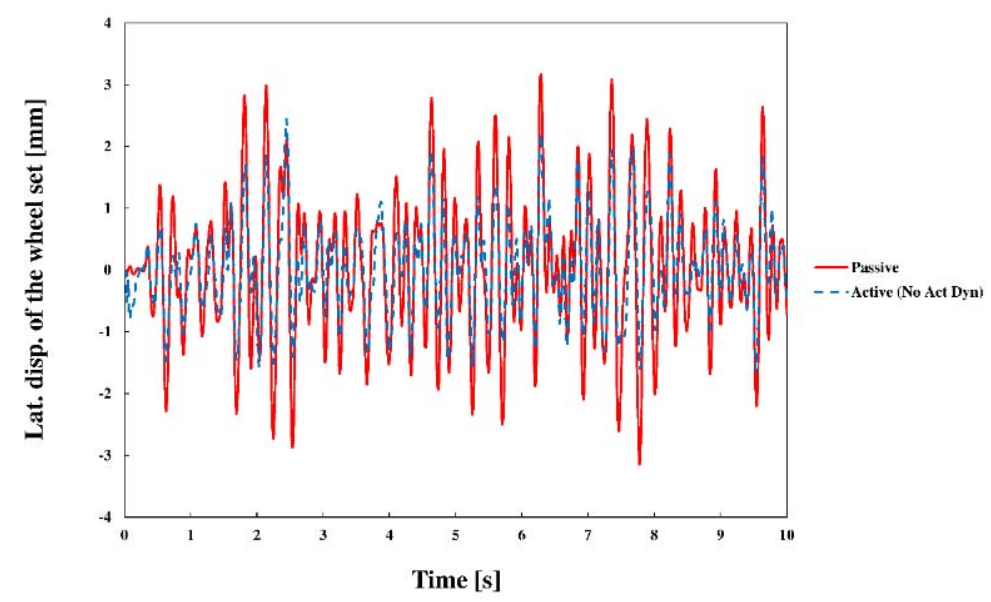

Figure 13: Lateral displacement of the leading axle: Active Vs. Passive control.

The PSD of the carbody's lateral acceleration and PSD of the leading axle's wear are plotted in Fig. 14 (a) and Fig. 14 (b), respectively. It can be seen that using the proposed robust controller ride comfort is improved in comparison with the passive case. The differences in the amplitudes of the wear PSD 
diagrams shown in Fig. 14 (b) for the active and passive cases are due to the fact that the actuators and passive components (spring and dampers in particular) have different structures and might affect the dynamics behaviour of the wheel set in different ways. The rout mean square (RMS) of the wear index showed that wear is slightly reduced with the aid of active control. However, wear is generally small when the vehicle operates on tracks with large curve radii and straight tracks.

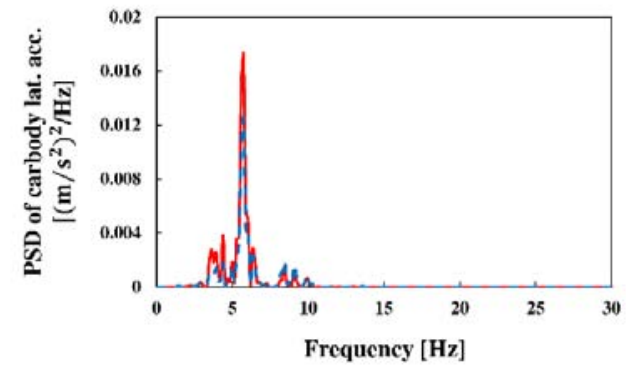

(a)

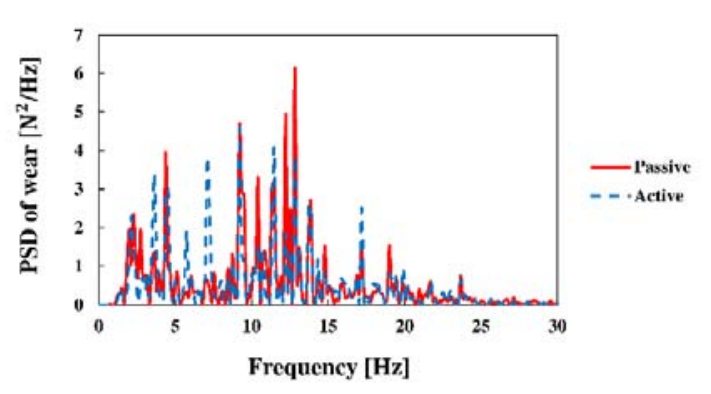

(b)

Figure 14: Active controller performance vs. passive: a) PSD of carbody lateral accelerations; b) PSD of wear.

To study the effects of the compensation technique on the dynamics performance of the vehicle, a suitable reference for comparison has to be chosen. The schematic diagram of the control strategy is plotted in Fig. 15 (a-c) for the ideal case (No Act Dyn) and the cases with actuator dynamics: with and without compensation. Here, blocks VM, Ctrl, Act, and Comp represent the vehicle model, controller, actuator model, and compensator, respectively. Vectors, $\mathbf{y}_{\mathrm{i}}$ and $\mathbf{f}_{\mathrm{i}}(\mathrm{i}=\mathrm{a}, \mathrm{b}, \mathrm{c})$ denote the vehicle's outputs and input control forces, respectively. The controller command in the case of no compensation is represented by $\mathbf{f}_{\mathrm{bc}}$. The ideal case (Fig. 15 (a)) and the respective vehicle's outputs and control force inputs are considered as the reference for comparison the vehicle performance with and without the compensation technique. It should be noted that only the lateral displacement and the control force applied to the leading axle are chosen for comparison.

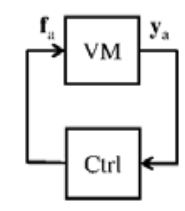

(a)

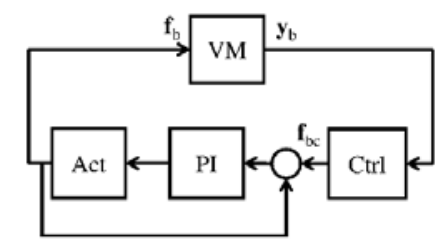

(b)

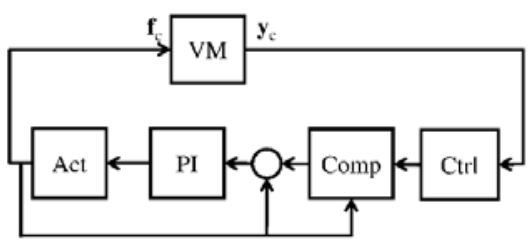

(c)

Figure 15: Schematic block diagram of the control technique for the ideal and the two cases with actuator dynamics: a) Ideal (No Act Dyn); b) Without compensation; c) With compensation.

The lateral displacement error (i.e. $\mathbf{y}_{\mathrm{b}}-\mathbf{y}_{\mathrm{a}}$ and $\mathbf{y}_{\mathrm{c}}-\mathbf{y}_{\mathrm{a}}$ ) of the leading axle and the actuator's output force error (i.e. $\mathbf{f}_{\mathrm{b}}-\mathbf{f}_{\mathrm{a}}$ and $\mathbf{f}_{\mathrm{c}}-\mathbf{f}_{\mathrm{a}}$ ) with respect to the ideal case (No Act Dyn) are compared in Figs. 16 (a), (b) for the case of with and without compensation. From Fig. 16 (a) it can be seen that the lateral displacement 
error in the case of without compensation grows rapidly, while remains within the same limits when the compensation technique is in use.

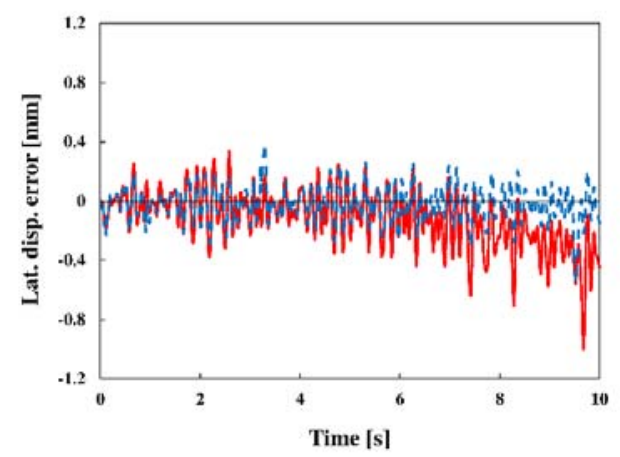

(a)

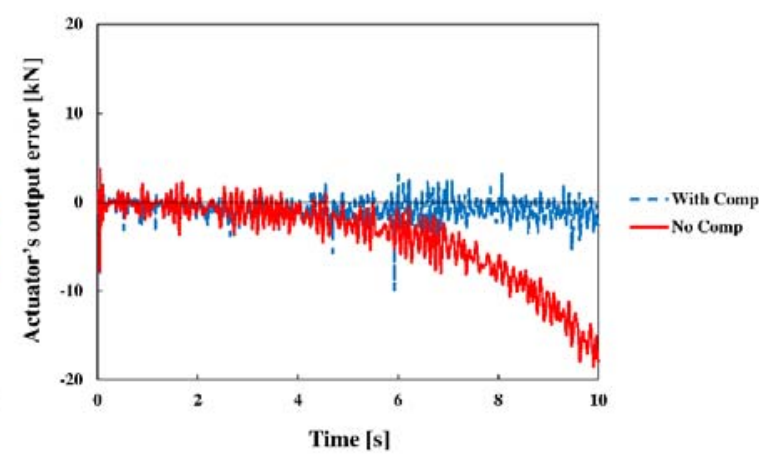

(b)

Figure 16: The error between the ideal case (No Act Dyn) and the two cases with actuator dynamics (with and without compensation): a) Wheel set's lateral displacement; b) Actuator's output force.

The respective actuator's output force errors for the case of with and without compensation reflect a similar behaviour and as the integration time increases, the error of the control force with respect to the ideal case remains within the same range for the case of with compensation technique, while it increases for the one associated with the case of no compensation, see Fig. 16 (b).

Such a behaviour might make the system unstable and has not been observed for the vehicle model with linear rail and wheel profiles. This proves the significance of the proposed compensation technique in practice once dealing with the nonlinear wheel and rail profiles.

It is important to note that for the case of control without compensation (Fig. 15 (b)), comparison of the actuator's output $\left(\mathbf{f}_{\mathrm{b}}\right)$ and the controller command $\left(\mathbf{f}_{\mathrm{bc}}\right)$ showed that the error (i.e. $\mathbf{f}_{\mathrm{b}}-\mathbf{f}_{\mathrm{bc}}$ ) is bounded. Consequently, the source of the noticeable difference with the ideal control force in Fig. 16 (b) might be the controller command $\left(\mathbf{f}_{\mathrm{bc}}\right)$. This could be due to the fact that the parameters of the dynamic weighting matrix $\left(\mathrm{W}_{\mathrm{fc}}\right.$ ) used to account the actuator dynamics during the control design process (see Fig. 2) might not be properly tuned from this point of view. Retuning the controller parameters showed that those errors can be reduced. As a result, using the proposed compensation technique or retuning the controller parameters might reduce the errors shown in Fig. 16.

Variations in the mass of carbody $\left(m_{\mathrm{v}}\right)$ can significantly affect the vehicle dynamics behaviour [27]. Therefore, the performance of the controller and compensation technique is checked from this perspective. In this regard, the initial carbody mass is decreased (by $45 \%$ ) and increased (by $142 \%$ ) which are the limit values employed in [27] to carry out the assessment analysis of the dynamics behaviour of a railway vehicle with respect to the inertia properties. The lateral accelerations of the 
leading bogie frame are compared in Fig. 17 for the case of initial, decreased, and increased carbody mass.

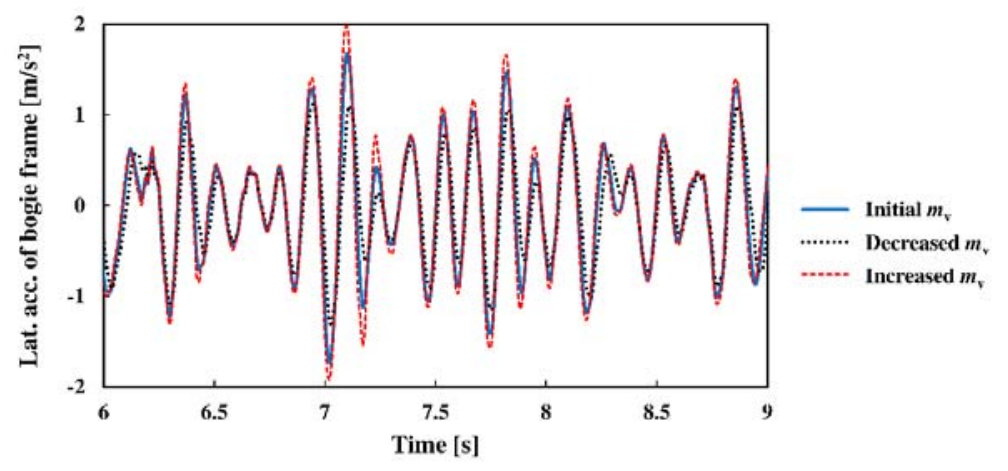

Figure 17: Lateral acceleration of the leading bogie for the initial, decreased and increased carbody mass.

It can be seen that regardless of the variations of the carbody mass, the proposed controller and compensation technique stabilise the system and lead to an appropriate vehicle dynamics behaviour.

\section{Conclusions}

A robust controller was designed based on the $\mathrm{H}_{\infty}$ concept to improve the steering and curving performance of railway vehicles with solid axle wheel sets. A half-car railway vehicle model with 7 DOF was considered for the control design purpose. The paper addressed the practical issues regarding control of railway vehicles by introducing accelerometers and angular velocity sensors to measure the lateral accelerations and yaw angular velocities of the wheel sets. Furthermore, actuator dynamics has been taken into account and ball-screw mechanical actuators were employed to apply the control torque to the vehicle model. In addition to a PI controller tuned to alleviate the actuator dynamics, a compensation technique was introduced. The procedure worked based on the online estimation of the actuator's time delay and accordingly modifying the control command to suppress the actuator dynamics effects. The controller performance was also tested on a full scale one-car railway vehicle model with 50 DOF developed in the multibody dynamics software SIMPACK.

The following concluding remarks have been achieved:

- The proposed robust controller stabilised the system and yield excellent curving performance.

- For the vehicle model with realistic structural parameters, nonlinear wheel and rail profiles, and input track data, the proposed robust controller has shown improvement in the vehicle's performance in comparison with the passive case.

- The proposed compensation technique demonstrated remarkable performance improvement for both vehicle types considered in this study. 
- Although the linear vehicle model run stable even without an actuator dynamics compensation, the simulation results proved the significant role of the proposed compensation technique in the system dynamics performance when nonlinearities such as realistic wheel and rail profiles are taken into account.

\section{Acknowledgements}

This study is a joint research work done at the Center of Excellence in Railway Mechanics (CHARMEC) at Chalmers University of Technology, Sweden and Control and Systems Engineering group at University of Salford Manchester, UK. The Ekman family foundation and Chalmers Stiftelsen are gratefully appreciated for the financial support of this research. Finally, the anonymous reviewers are cordially acknowledged for their fruitful comments which improved the quality of this paper.

\section{Disclosure statement}

No potential conflict of interest was reported by the authors.

\section{Appendix}

The explicit expressions for matrices $A, B$, and $\Gamma$ in Eq. (8) used to represent the system state space model are given as follows:

$$
\mathrm{A}=\left[\begin{array}{cccccccccccccc}
a_{1,1} & a_{1,2} & 0 & a_{1,4} & 0 & 0 & 0 & 0 & a_{1,9} & a_{1,10} & a_{1,11} & a_{1,12} & 0 & 0 \\
a_{2,1} & 0 & 0 & 0 & 0 & 0 & 0 & 0 & 0 & 0 & 0 & 0 & 0 & 0 \\
0 & a_{3,2} & a_{3,3} & 0 & 0 & 0 & 0 & 0 & 0 & 0 & 0 & 0 & 0 & 0 \\
0 & 0 & a_{4,3} & 0 & 0 & 0 & 0 & 0 & 0 & 0 & 0 & 0 & 0 & 0 \\
0 & 0 & 0 & 0 & a_{5,5} & a_{5,6} & 0 & a_{5,8} & a_{5,9} & a_{5,10} & a_{5,11} & a_{5,12} & 0 & 0 \\
0 & 0 & 0 & 0 & a_{6,5} & 0 & 0 & 0 & 0 & 0 & 0 & 0 & 0 & 0 \\
0 & 0 & 0 & 0 & 0 & a_{7,6} & a_{7,7} & 0 & 0 & 0 & 0 & 0 & 0 & 0 \\
0 & 0 & 0 & 0 & 0 & 0 & a_{8,7} & 0 & 0 & 0 & 0 & 0 & 0 & 0 \\
a_{9,1} & a_{9,2} & 0 & 0 & a_{9,5} & a_{9,6} & 0 & 0 & a_{9,9} & a_{9,10} & 0 & 0 & a_{9,13} & a_{9,14} \\
0 & 0 & 0 & 0 & 0 & 0 & 0 & 0 & a_{10,9} & 0 & 0 & 0 & 0 & 0 \\
a_{11,1} & a_{11,2} & 0 & 0 & a_{11,5} & a_{11,6} & 0 & 0 & 0 & 0 & a_{11,11} & a_{11,12} & 0 & 0 \\
0 & 0 & 0 & 0 & 0 & 0 & 0 & 0 & 0 & 0 & a_{12,11} & 0 & 0 & 0 \\
0 & 0 & 0 & 0 & 0 & 0 & 0 & 0 & a_{13,9} & a_{13,10} & 0 & 0 & a_{13,13} & a_{13,14} \\
0 & 0 & 0 & 0 & 0 & 0 & 0 & 0 & 0 & 0 & 0 & 0 & a_{14,13} & 0
\end{array}\right]_{14 \times 14}
$$

here,

$$
\begin{aligned}
& a_{1,1}=-\left(2 f_{22} / V_{\mathrm{s}}+C_{\mathrm{p}}\right) / m_{\mathrm{w}}, \quad a_{1,2}=-K_{\mathrm{p}} / m_{\mathrm{w}}, \quad a_{1,4}=2 f_{22} / m_{\mathrm{w}}, \quad a_{1,9}=C_{\mathrm{p}} / m_{\mathrm{w}}, \\
& a_{1,10}=K_{\mathrm{p}} / m_{\mathrm{w}}, \quad a_{1,11}=\left(C_{\mathrm{p}} L_{\mathrm{v}}\right) / m_{\mathrm{w}}, \quad a_{1,12}=\left(K_{\mathrm{p}} L_{\mathrm{v}}\right) / m_{\mathrm{w}}, \\
& a_{2,1}=1,
\end{aligned}
$$




$$
\begin{aligned}
& a_{3,2}=-\left(2 f_{11} \lambda L_{\mathrm{g}}\right) /\left(r_{0} I_{\mathrm{w}}\right), a_{3,3}=-\left(2 f_{11} L_{\mathrm{g}}^{2}\right) /\left(V_{\mathrm{s}} I_{\mathrm{w}}\right), \\
& a_{4,3}=1, \\
& a_{5,5}=a_{1,1}, \quad a_{5,6}=a_{1,2}, \quad a_{5,8}=a_{1,4}, \quad a_{5,9}=a_{1,9}, \\
& a_{5,10}=a_{1,10}, \quad a_{5,11}=-a_{1,11}, \quad a_{5,12}=-a_{1,12}, \\
& a_{6,5}=1, \\
& a_{7,6}=a_{3,2}, \quad a_{7,7}=a_{3,3}, \\
& a_{8,7}=1, \\
& a_{9,1}=C_{\mathrm{p}} / m_{\mathrm{b}}, \quad a_{9,2}=K_{\mathrm{p}} / m_{\mathrm{b}}, \quad a_{9,5}=a_{9,1}, \quad a_{9,6}=a_{9,2}, \\
& a_{9,9}=-\left(2 C_{\mathrm{p}}+C_{\mathrm{s}}\right) / m_{\mathrm{b}}, \quad a_{9,10}=-\left(2 K_{\mathrm{p}}+K_{\mathrm{s}}\right) / m_{\mathrm{b}}, \quad a_{9,13}=C_{\mathrm{s}} / m_{\mathrm{b}}, \quad a_{9,14}=K_{\mathrm{s}} / m_{\mathrm{b}}, \\
& a_{10,9}=1 \\
& a_{11,1}=\left(L_{\mathrm{v}} C_{\mathrm{p}}\right) / I_{\mathrm{b}}, \quad a_{11,2}=\left(L_{\mathrm{v}} K_{\mathrm{p}}\right) / I_{\mathrm{b}}, \quad a_{11,5}=-\left(L_{\mathrm{v}} C_{\mathrm{p}}\right) / I_{\mathrm{b}}, \quad a_{11,6}=-\left(L_{\mathrm{v}} K_{\mathrm{p}}\right) / I_{\mathrm{b}}, \\
& a_{11,11}=-2 L_{\mathrm{v}}^{2} C_{\mathrm{p}} / I_{\mathrm{b}}, \quad a_{11,12}=-2 L_{\mathrm{v}}^{2} K_{\mathrm{p}} / I_{\mathrm{b}}, \\
& a_{12,11}=1 \text {, } \\
& a_{13,9}=C_{\mathrm{s}} / m_{\mathrm{v}}, \quad a_{13,10}=K_{\mathrm{s}} / m_{\mathrm{v}} \quad, \quad a_{13,13}=-C_{\mathrm{s}} / m_{\mathrm{v}}, a_{13,14}=-K_{\mathrm{s}} / m_{\mathrm{v}}, \\
& a_{14,13}=1 \text {. } \\
& \mathrm{B}=\left[\begin{array}{cccccccccccccc}
0 & 0 & b_{3,1} & 0 & 0 & 0 & 0 & 0 & 0 & 0 & b_{11,1} & 0 & 0 & 0 \\
0 & 0 & 0 & 0 & 0 & 0 & b_{7,2} & 0 & 0 & 0 & b_{11,2} & 0 & 0 & 0
\end{array}\right]_{2 \times 14}^{\mathrm{T}}
\end{aligned}
$$

where,

$b_{3,1}=1 / I_{\mathrm{w}}, \quad b_{7,2}=1 / I_{\mathrm{w}}, \quad b_{11,1}=-1 / I_{\mathrm{b}}, \quad b_{11,2}=-1 / I_{\mathrm{b}}$.

$$
\Gamma=\left[\begin{array}{cccccccccccccc}
\gamma_{1,1} & 0 & \gamma_{3,1} & 0 & 0 & 0 & 0 & 0 & \gamma_{9,1} & 0 & 0 & 0 & \gamma_{13,1} & 0 \\
\gamma_{1,2} & 0 & 0 & 0 & 0 & 0 & 0 & 0 & \gamma_{9,2} & 0 & 0 & 0 & \gamma_{13,2} & 0 \\
0 & 0 & 0 & 0 & \gamma_{5,3} & 0 & \gamma_{7,3} & 0 & \gamma_{9,3} & 0 & 0 & 0 & \gamma_{13,3} & 0 \\
0 & 0 & 0 & 0 & \gamma_{5,4} & 0 & 0 & 0 & \gamma_{9,4} & 0 & 0 & 0 & \gamma_{13,4} & 0 \\
0 & 0 & \gamma_{3,5} & 0 & 0 & 0 & 0 & 0 & 0 & 0 & 0 & 0 & 0 & 0 \\
0 & 0 & 0 & 0 & 0 & 0 & \gamma_{7,6} & 0 & 0 & 0 & 0 & 0 & 0 & 0
\end{array}\right]_{6 \times 14}^{\mathrm{T}}
$$

here, 
$\gamma_{1,1}=V_{\mathrm{s}}^{2}, \quad \gamma_{1,2}=-g$,

$\gamma_{3,1}=\left(2 f_{11} L_{\mathrm{g}}^{2}\right) / I_{\mathrm{w}}, \quad \gamma_{3,5}=\left(2 f_{11} \lambda L_{\mathrm{g}}\right) /\left(r_{0} I_{\mathrm{w}}\right)$,

$\gamma_{5,3}=\gamma_{1,1}, \quad \gamma_{5,4}=\gamma_{1,2}$,

$\gamma_{7,3}=\gamma_{3,1}, \quad \gamma_{7,6}=\gamma_{3,5}$,

$\gamma_{9,1}=V_{\mathrm{s}}^{2} / 2, \quad \gamma_{9,2}=-g / 2, \quad \gamma_{9,3}=\gamma_{9,1}, \quad \gamma_{9,4}=\gamma_{9,2}$,

$\gamma_{13,1}=\gamma_{9,1}, \quad \gamma_{13,2}=\gamma_{9,2}, \quad \gamma_{13,3}=\gamma_{13,1}, \quad \gamma_{13,4}=\gamma_{13,2}$.

The matrices $B_{1}, B_{2}, C_{1}, C_{2}, D_{11}, D_{12}, D_{21}$, and $D_{22}$ used in Eqs. (11) and (12) to represent the augmented state space form of the system equations are defined as:

$\mathrm{B}_{1}=0_{14 \times 4}$,

$\mathrm{B}_{2}=\left[\begin{array}{ll}\Gamma & \mathrm{B}\end{array}\right]_{14 \times 8}$,

where, matrices $\Gamma$ and B are introduced by Eqs. (A-3) and (A-2), respectively.

$\mathrm{C}_{1}=\left[\begin{array}{llllllllllllll}0 & 1 & 0 & 0 & 0 & 0 & 0 & 0 & 0 & 0 & 0 & 0 & 0 & 0 \\ 0 & 0 & 0 & 0 & 0 & 1 & 0 & 0 & 0 & 0 & 0 & 0 & 0 & 0 \\ 0 & 0 & 0 & 0 & 0 & 0 & 0 & 0 & 0 & 0 & 0 & 0 & 0 & 0 \\ 0 & 0 & 0 & 0 & 0 & 0 & 0 & 0 & 0 & 0 & 0 & 0 & 0 & 0\end{array}\right]_{4 \times 14}$

$\mathrm{C}_{2}=\left[\begin{array}{cccccccccccccc}a_{1,1} & a_{1,2} & 0 & a_{1,4} & 0 & 0 & 0 & 0 & a_{1,9} & a_{1,10} & a_{1,11} & a_{1,12} & 0 & 0 \\ 0 & 0 & a_{4,3} & 0 & 0 & 0 & 0 & 0 & 0 & 0 & 0 & 0 & 0 & 0 \\ 0 & 0 & 0 & 0 & a_{5,5} & a_{5,6} & 0 & a_{5,8} & a_{5,9} & a_{5,10} & a_{5,11} & a_{5,12} & 0 & 0 \\ 0 & 0 & 0 & 0 & 0 & 0 & 0 & a_{8,7} & 0 & 0 & 0 & 0 & 0 & 0\end{array}\right]_{4 \times 14}$

$\mathrm{D}_{11}=0_{4 \times 10}$,

$\mathrm{D}_{12}=\left[\begin{array}{llll}0 & 0 & 1 & 0 \\ 0 & 0 & 0 & 1\end{array}\right]_{2 \times 4}^{\mathrm{T}}$,

$\mathrm{D}_{11}=\left[\begin{array}{cccccccccc}1 & 0 & 0 & 0 & 0 & 0 & 0 & 0 & 0 & 0 \\ 0 & 1 & 0 & 0 & 0 & 0 & 0 & 0 & 0 & 0 \\ 0 & 0 & 1 & 0 & 0 & 0 & 0 & 0 & 0 & 0 \\ 0 & 0 & 0 & 1 & 0 & 0 & 0 & 0 & 0 & 0\end{array}\right]_{4 \times 10}$

$\mathrm{D}_{11}=0_{4 \times 2}$. 


\section{References}

[1] Sun, S., Deng, H., Li, W., Du, H., Ni, Y.Q., Zhang, J., and Yang, J., Improving the critical speeds of high-speed trains using magnetorheological technology, Smart Materials and Structures, 2013, 22, doi:10.1088/0964-1726/22/11/115012.

[2] Zong, L.H., Gong, X.L., Xuan, S.H., and Guo, C.Y., Semi-active Ho control of high-speed railway vehicle suspension with magnetorheological dampers, Vehicle System Dynamics, 2013, 51(5): pp. 600-626.

[3] Nakajima, T., Shimokawa, Y., Mizuno, M., and Sugiyama, H., Air suspension system model coupled with leveling and differential pressure valves for railroad vehicle dynamics simulation, Journal of Computational and Nonlinear Dynamics, 2014, 9: pp. 1-9.

[4] Matamoros-Sanchez, A.Z. and Goodall, R.M., Novel mechatronic solutions incorporating inerters for railway vehicle vertical secondary suspensions, Vehicle System Dynamics, 2015, 53(2): pp. 113-136.

[5] Mousavi Bideleh, S.M., Berbyuk, V., and Persson, R., Wear/comfort Pareto optimisation of bogie suspension, Vehicle System Dynamics, 2016, 54(8): pp. 1053-1076, doi: 10.1080/00423114.2016.1180405.

[6] Mousavi-Bideleh, S.M. and Berbyuk, V., Multiobjective optimisation of bogie suspension to boost speed on curves, Vehicle System Dynamics, 2016, 54(1): pp. 58-85, doi: 10.1080/00423114.2015.1114655.

[7] Orvnäs, A., Stichel, S., and Persson, R., Active lateral secondary suspension with Hoo control to improve ride comfort: simulations on a full-scale model, Vehicle System Dynamics, 2011, 49(9): pp. 1409-1422.

[8] Colombo, E.F., Gialleonardo, E.D., Facchinetti, A., and Bruni, S., Active carbody roll control in railway vehicles using hydraulic actuation, Control Engineering Practice, 2014, 31: pp. 2434.

[9] Gajdar, T., Suda, Y., Korondi, P., and Hashimoto, H., Observer based robust Hœ control design for rail guidance systems IECON Proceedings (Industrial Electronics Conference), 1997, 1: pp. $138-142$.

[10] Mei, T.X. and Goodall, R.M., Recent development in active steering of railway vehicles, Vehicle System Dynamics, 2003, 39(6): pp. 415-436.

[11] Shen, S., Mei, T.X., Goodall, R.M., Pearson, J., and Himmelstein, G., A study of active steering strategies for railway bogie, Vehicle System Dynamics, 2004, 41: pp. 282-291.

[12] Mei, T.X., Shen, S., Goodall, R.M., and Pearson, J.T. Active steering control for railway bogies based on displacement measurments, in 16th Triennial World Congress of International Federation of Automatic Control, IFAC. 2005. Prague; Czech Republic. 
[13] Pearson, J.T., Goodall, R.M., Mei, T.X., and Himmelstein, G., Active stability control strategies for a high speed bogie, Control Engineering Practice, 2004, 12: pp. 1381-1391.

[14] Mei, T.X. and Goodall, R.M., Robust Control for Independently Rotating Wheelsets on a Railway Vehicle Using Practical Sensors, IEEE Transactions on Control Systems Technology, 2001, 9(4): pp. 599-607.

[15] Zhang, X.-M., MinWu, Jin-Hua She, and He, Y., Delay-dependent stabilization of linear systems with time-varying state and input delays, Automatica, 2005, 41: pp. 1405-1412.

[16] Chen, B., Liu, X.-P., Tong, S.-C., and Lin, C., Observer-Based Stabilization of T-S Fuzzy Systems With Input Delay, IEEE TRANSACTIONS ON FUZZY SYSTEMS, 2008, 16(3): pp. 652-663.

[17] Li, H., Liu, H., Gao, H., and Shi, P., Reliable Fuzzy Control for Active Suspension Systems With Actuator Delay and Fault, IEEE TRANSACTIONS ON FUZZY SYSTEMS, 2012, 20(2): pp. 342-357.

[18] Shin, D., Lee, G., Yi, K., and Noh, K., Motorized vehicle active suspension damper control with dynamic friction and actuator delay compensation for a better ride quality, Proc IMechE Part D: J Automobile Engineering, 2015: pp. 1-16, doi: 0.1177/0954407015598670.

[19] Kalker, J.J., Three-Dimensional Elastic Bodies in Rolling Contact. 1990, Kluwer, Dordrecht, Netherlands.

[20] Mousavi Bideleh, S.M. and Berbyuk, V. Variance-Based Wheel/Rail Contact Sensitivity Analysis in Respect of Wheelset Dynamics, in The ASME 11th International Conference on Multibody Systems, Nonlinear Dynamics, and Control, Paper DETC2015-47342. 2015. Boston, Massachusetts, USA. doi: 10.1115/DETC2015-47342.

[21] Mousavi Bideleh, S.M. and Berbyuk, V., Global sensitivity analysis of bogie dynamics with respect to suspension components, Multibody System Dynamics, 2016, 37(2): pp. 145-174, doi: 10.1007/s11044-015-9497-0.

[22] Mei, T.X., Foo, T.H.E., and Goodall, R.M. Genetic Algorithms for Optimising Active Controls in Railway Vehicles, in Inst. Elect. Eng. Colloq. Optimization Contr.: Methods Applicat. 1998. London, U. K., (98/521).

[23] Pacchioni, A., Goodall, R.M., and Bruni, S., Active suspension for a two-axle railway vehicle, Vehicle System Dynamics, 2010, 48: pp. 105-120, doi: 10.1080/00423111003668252.

[24] Wang, P., Mei, T., Zhang, J., and Li, H., Self-powered Active Lateral Secondary Suspension for Railway Vehicles, IEEE Transactions on Vehicular Technology, 2015, doi: 10.1109/TVT.2015.2407575.

[25] Ahmadizadeh, M., Mosqueda, G., and Reinhorn, A.M., Compensation of actuator delay and dynamics for real-time hybrid structural simulation, Earthquake Engineering and Structural Dynamics, 2008, 37: pp. 21-42. 
[26] Horiuchi, T., Inoue, M., Konno, T., and Namita, Y., Real-Time Hybrid Experimental System with Actuator Delay Compensation and its Application to a Piping System with Energy Absorber, Earthquake Engng. Struct. Dyn, 1999, 28: pp. 1121-1141.

[27] Suarez, B., Felez, J., Maroto, J., and Rodriguez, P., Sensitivity analysis to assess the influence of the inertial properties of railway vehicle bodies on the vehicle's dynamic behaviour, Vehicle System Dynamics, 2013, 51(2): pp. 251-279. 